Artigo original

Hegemonia - Revista Eletrônica de Relações Internacionais do Centro Universitário Unieuro

ISSN: $1809-1261$

UNIEURO, Brasília, número 15, 2015, pp. 151-183.

Recebido em: 20/3/2015

Avaliado em:12/4/2015

Aprovado em: 18/5/2015

\title{
A Busca da Inclusão Financeira através da Bancarização Pública Brasileira
}

Luiz Augusto Oliveira Leite ${ }^{1}$

Resumo: O objetivo deste artigo é demonstrar que o papel do banco público brasileiro no processo de bancarização é atuar como principal agente das políticas públicas do governo federal, que além de promover a inclusão social, como forma de desenvolvimento econômico, deve garantir que os direitos fundamentais positivados na Carta Magna sejam aplicados a camada marginalizada pelo sistema. Ressalte-se que a lutas sociais e manifestações políticas fortalecem e legitimam as reivindicações populares. A inserção dos excluídos no mercado de trabalho promove a garantia do mínimo de bem estar social e gera recursos para dinâmica do mercado financeiro. Neste contexto em que a mundialização do capitalismo solapou os direitos sociais de grande parte da população, o Estado deve agir de forma eficaz para diminuir os efeitos negativos gerados pela crescente disputa ao mercado de trabalho globalizado. Portanto, a bancarização no setor público não pode ser vista apenas como um novo "nicho mercadológico", mas como uma maneira de capitar e capacitar a população desprovida de recursos laborais, bem como disseminar a educação financeira.

Palavras-chave: Bancarização, políticas públicas, setor público, inclusão social, políticas.

Abstract: The purpose of this article is to demonstrate that the role of the Brazilian public bank in the banking process is to act as the main agent of

$1 \quad$ Mestre em Ciência Política. 
Artigo original

Hegemonia - Revista Eletrônica de Relações Internacionais do Centro Universitário Unieuro

ISSN: $1809-1261$

UNIEURO, Brasília, número 15, 2015, pp. 151-183.

public policies of the federal government, which in addition to promoting social inclusion as a means of economic development, should ensure that the rights positivized fundamental in the Constitution are applied to layer marginalized by the system. It should be noted that the social struggles and political demonstrations strengthen and legitimate popular demands. The inclusion of the excluded in the labor market promotes the guarantee of minimum social welfare and generates resources for financial market dynamics. In this context in which the globalization of capitalism undermined the social rights of much of the population, the state should take effective action to reduce the negative effects generated by the growing dispute to the globalized labor market. Therefore, the banking in the public sector can not be seen only as a new "market niche", but as a way to capitar and empower the population devoid of labor resources, and disseminate financial education.

Keywords: Bankarization, public policy, public sector, social inclusion policies.

\section{INTRODUÇÃO}

O desenvolvimento do capitalismo mercantilista, a influência dominante da burguesia e os anseios sociais, geraram o aumento da competitividade no mercado de trabalho, que com a globalização, a necessidade de capacitação pessoal, tornou-se inevitável.

Neste contexto, a exclusão social da população sem acesso às ferramentas de capacitação laboral aumentou e os benefícios do progresso não foram distribuídos de forma igualitária pelo povo brasileiro, que ficou à margem do sistema financeiro por décadas.

A responsabilidade do Estado é garantir a cidadania, bem como resolver os problemas emergentes, uma vez que a concentração de riqueza e a disputa territorial prejudicaram o pleno exercício dos direitos políticos e patrimoniais da população desfavorecida. 
Artigo original

Hegemonia - Revista Eletrônica de Relações Internacionais do Centro Universitário Unieuro

ISSN: $1809-1261$

UNIEURO, Brasília, número 15, 2015, pp. 151-183.

Desta forma, a camada sem proventos que por décadas foi marginalizada, passou a ser vista como uma nova fonte de captação de "clientes" para disseminar a marca dos bancos no mercado econômico. A inclusão desta classe no sistema financeiro tornou-se uma nova forma de competição entre as Instituições do setor.

Os antigos explorados que lutaram por liberdade, são em grande parte excluídos, pela falta de proteção e negligência do Estado perante os direitos sociais. Estes foram massificados pelo exercício do autoritarismo e da violência crescente gerada pela disputa globalizada.

A eliminação da inflação permitiu o início de uma era de expansão das fronteiras mercadológicas, de novas relações comerciais e de inovações tecnológicas para atender as diferentes classes de "clientes". Neste sentido, o banco público deve alinhar seu plano estratégico e empresarial à visão de bem estar social e do Estado de Liberdade.

Para Muhammad Yunus que começou com um banco em Bangladesh e tirou da pobreza milhares de famílias no país e Ihe rendeu, 30 anos depois o Premio Nobel da Paz em 2006, é possível livrar o mundo da pobreza se estivermos determinados a isso. Esta conclusão não é fruto de uma esperança crédula, mas o resultado concreto da experiência que adquirimos em nossa prática de microcrédito.

No mesmo sentido, em sua vinda ao Brasil, Muhammad Yunus afirmou que "oferecer bem-estar social é importante, mas dar oportunidade para as pessoas saírem do programa de bem-estar social é ainda mais importante. Suas políticas de microcrédito são um exemplo de fortalecimento a economia pautada na liberdade humana e no potencial ilimitado do cidadão. 
Artigo original

Hegemonia - Revista Eletrônica de Relações Internacionais do Centro Universitário Unieuro

ISSN: $1809-1261$

UNIEURO, Brasília, número 15, 2015, pp. 151-183.

As políticas públicas que visam a capacitação laboral e o desenvolvimento produtivo de empreendedores populares geram transformações no indivíduo, na sociedade e no mercado.

O desenvolvimento laboral forma na coletividade uma garantia em relação aos direitos de propriedade, do indivíduo, da participação política e do conceito de justiça. Além disso, face à sua nova condição, agora de cidadão, também assume deveres frente ao Estado, garante-se a democracia e a relação contratual.

No Brasil, Monzoni Neto (2006) conduziu uma avaliação de impacto sobre a renda dos microempreendedores e demonstrou que o impacto do microcrédito na geração de renda é significativo: em dois anos, a renda do microempreendedor quase que dobra. Resta comprovado que o benefício concedido de forma a promover inclusão financeira orientada, altera a situação social do beneficiário frente ao sistema financeiro.

Nesta linha é possível compreender que os empreendedores populares são um público extremamente importante, em grande medida, com necessidades financeiras que não atendidas pelo setor bancário tradicional.

Segundo dados do IBGE mais de $1 / 4$ da população ocupada refere-se a trabalhadores por conta-própria e a empregadores com até 2 empregados (1,8 milhões de empregadores). Desta forma, é necessário expansão do microcrédito produtivo no Brasil, bem como o fortalecimento do papel das instituições especializadas em microfinanças para aumento gradativo da inclusão financeira, tendo em vista a necessidade de reinserção no mercado de trabalho.

Conforme o V Fórum do Banco Central que ocorreu este ano em Fortaleza, para uma inclusão financeira de qualidade é necessário ter como 
Artigo original

Hegemonia - Revista Eletrônica de Relações Internacionais do Centro Universitário Unieuro

ISSN: $1809-1261$

UNIEURO, Brasília, número 15, 2015, pp. 151-183.

premissas a importância da educação financeira, da proteção e da inovação.

De acordo com os dados da Febraban, $44 \%$ da população adulta no Brasil ainda não é bancarizada, desta forma é preciso que os bancos públicos atuem em linhas de microcrédito com foco crescente no microcrédito produtivo orientado, o que favorecerá o público-alvo de indivíduos exclusos do sistema.

Importantes parcerias servem como auxílio para o estudo de políticas de educação financeira, que visam a permanência destes indivíduos, após sua inclusão inicial. Desta maneira o Plano Brasil sem Miséria, o Programa Nacional de Microcrédito Crescer e o Programa Crescer são iniciativas que possibilitam a entrada no mercado de bancos públicos de grande porte, que já operam de acordo com as regras do programa, aumentando a possibilidade de acesso ao sistema bancário mediante ações de educação financeira e incentivos financeiros voltados a produtividade.

Destarte, o novo cenário criado pela recente bancarização foi fortemente influenciado pelas idéias burguesas de livre comércio, de Estado Mínimo, de participação política restrita, de leis protecionistas e manutenção do poder. Os bancos públicos devem intervir nesta realidade, uma vez que são o elo entre o cidadão, o Estado e o sistema financeiro, mudando a realidade de uma ação protecionista para uma política voltada a reinserção no mercado de trabalho e movimentação financeira.

Para Muller (2014) o direito é uma forma que o indivíduo tem razoavelmente de exigir da sociedade a garantia que são positivadas e conquistadas pelas lutas sociais, por ser assim o direito às prestações, às obrigações internas e interpretações externas devem ser submetidas no contexto sócio político para verificação de análise do fato como socialmente possível e calculatoriamente desejado. 
Artigo original

Hegemonia - Revista Eletrônica de Relações Internacionais do Centro Universitário Unieuro

ISSN: $1809-1261$

UNIEURO, Brasília, número 15, 2015, pp. 151-183.

Não podemos ignorar que a ordem jurídica do Estado constitucional burguês da modernidade reduziu a um mínimo, a expressão normativa imediata para tratar da desigualdade social e das diferenças estatamentais ou de classe.

Portanto a bancarização no setor público deve proporcionar transformações significativas que beneficiarão os excluídos do sistema financeiro por problemas relacionados à globalização e incapacidade de trabalho.

Neste sentido, estas ações de políticas públicas são uma forma de minimizar a injustiça social, tão presente quanto a justiça ora proclamada pelas lutas políticas. Ressalte-se que a educação financeira é uma forma de proporcionar a permanência destes indivíduos neste sistema e assim fazer jus aos direitos fundamentais de segunda geração.

Para Hofling (2001):

Mais do que oferecer "serviços" sociais - entre eles a educação - as ações públicas, articuladas com as demandas da sociedade, devem se voltar para a construção de direitos sociais.

1. Desenvolvimento econômico globalizado e a exclusão social devido a negligencia do Estado brasileiro na garantia da cidadania

O Estado de Bem Estar Social é uma característica conceitual e está presente na definição dos direitos coletivos e difusos dos Estados Contemporâneos. Destaca-se que apenas parte da população usufrui deste conceito, uma vez que o descuido do Estado é uma realidade que atinge a parcela que não consegue desenvolver suas habilidades laborais, 
Artigo original

Hegemonia - Revista Eletrônica de Relações Internacionais do Centro Universitário Unieuro

ISSN: $1809-1261$

UNIEURO, Brasília, número 15, 2015, pp. 151-183.

ficando privada de liberdade, do desenvolvimento individual e da inclusão social.

Vale frisar que as camadas sociais mais baixas da população, apesar de organizáveis, não são organizadas. Elas são pouco representadas nas associações existentes, em suas posições de liderança e no direito administrativo; torna-se mais notório, pois a burocracia rege a sua aplicação organizada.

No âmbito dos Direitos Fundamentais em que dados políticos estão inseridos, reivindicar jurídico-políticamente a ordem liberal e democrática, deve ter a preocupação de igualdade nos componentes de clamor social conforme ao Estado de Direito, para que garantias desse Estado de Direito também não retrocedam ou sejam retiradas ao mesmo tempo.

Sendo assim, o Brasil é um país que jamais alcançou plenamente um modelo de Estado de Bem Estar Social, tendo em vista a dificuldade de promover em conjunto os três pilares da cidadania, ou seja, a promoção dos direitos sociais, políticos e civis. Desta forma, a sociedade demorou a exigir soluções democráticas e impor maior representação política das classes excluídas.

Para Carvalho (2006):

Para promoção da cidadania no Brasil os direitos sociais precedem os políticos e civis, diferente da Inglaterra que os direitos políticos precedem os civis e sociais.

Para garantir o equilíbrio da sociedade frente às desigualdades sociais é necessário promover políticas públicas, como as de inclusão financeira que valorizam a produtividade do indivíduo e estimulam o crescimento nas três dimensões do conceito de sustentabilidade, quais sejam: ambiental, econômica e soacial. (BANCO CENTRAL 2011) 
Artigo original

Hegemonia - Revista Eletrônica de Relações Internacionais do Centro Universitário Unieuro

ISSN: $1809-1261$

UNIEURO, Brasília, número 15, 2015, pp. 151-183.

Penso que uma administração pública - informada por uma concepção crítica de Estado - que considere sua função atender a sociedade como um todo, não privilegiando os interesses dos grupos detentores do poder econômico, deve estabelecer como prioritários programas de ação universalizantes, que possibilitem a incorporação de conquistas sociais pelos grupos e setores desfavorecidos, visando à reversão do desequilíbrio social. (HOFLING 2001)

Na questão do direito administrativo, no tocante à igualdade de todos, a teoria do bem comum político deveria ser em geral, a teoria do bem comum, pois com relação ao planejamento se mostra logo a elaboração de uma teoria para prática democrática e de planejamento do Estado Social e não deixa indicados elementos essenciais da teoria constitucional, designadamente da concepção de democracia do Estado Constitucional do cidadão.

Segundo o Banco Central do Brasil (2011), é necessário vencer os desafios, a fim de manter a inclusão financeira de forma permanente, ou seja, desenvolver canais de distribuição adequados que permitam que pessoas antes totalmente excluídas dos sistemas financeiros formais tenham acesso a esses serviços e condição de decisão sobre seu uso para atendimento às suas necessidades, diminuindo a desigualdade do acúmulo de riquezas do capitalismo mundializado.

Os grandes blocos econômicos no mundo atual marcam a estratégia da globalização e trouxe uma nova realidade ao comércio mundial, em que o livre comércio, a moeda única e a unificação de impostos são uma realidade cada vez mais presente.

Neste sentido, a formação dos bolsões da massa excludente é uma realidade, que no contexto brasileiro, a parcela afetada tornou-se marginalizada e esta a mercê de ações públicas que visam soluções 
Artigo original

Hegemonia - Revista Eletrônica de Relações Internacionais do Centro Universitário Unieuro

ISSN: $1809-1261$

UNIEURO, Brasília, número 15, 2015, pp. 151-183.

imediatas para os problemas sociais como: a falta de capacitação dos trabalhadores, a disputa pelo poder da classe burguesa, a exclusão social e educacional.

Percebe-se que a exclusão social no sistema financeiro brasileiro, em parte é o fruto da competição capitalista, que massificou a classe desprotegida e distanciou-a da possibilidade de viver dignamente, em meio ao processo evolutivo de suas capacidades laborais.

Para Salvador (2010):

O nosso país encontra-se entre as dez economias mais ricas do mundo e uma das maiores concentrações de renda do planeta. Nosso principal problema é a desigualdade.

A distância entre o Estado brasileiro e a população tende a aumentar, uma vez que o Brasil está incluído no bloco hegemônico do MERCOSUL, visando maior influência mundial. Esta disputa gera o desvio das funções basilares do Estado para uma função comercial e diplomática.

Para Adam Smith (1983):

A não-intervenção do Estado na economia é um Estado limitado às funções de guardião da segurança pública, mantenedor da ordem e garantia da propriedade privada.

As atuais manifestações foram uma resposta ao capitalismo que conceituou a liberdade, igualdade e gerou uma sensação de negligência do Estado pela sua característica protecionista.

Esta ação protecionista anula a eficácia de políticas públicas de inserção laboral, devido ao comodismo da população, que pela falsa ideia de benefício, não busca desenvolver suas habilidades pessoais. 
Artigo original

Hegemonia - Revista Eletrônica de Relações Internacionais do Centro Universitário Unieuro

ISSN: $1809-1261$

UNIEURO, Brasília, número 15, 2015, pp. 151-183.

Yunus afirma que é preciso muito mais do que programas como o Bolsa Família para ajudar as famílias de baixa renda, pois é preciso criar oportunidades para combater de vez a pobreza. Neste contexto, investir em negócios sociais é uma forma de motivar os microemprendedores a impulsionar a economia, bem como gerar a movimentação do comercio local.

A iniciativa do negócio social é investir em empresas voltadas a resolver problemas sociais em comunidades pobres.

Para François Chesnais (1996):

A própria economia (bancária) mundializada, que se volta para os mercados excluídos do consumo de seus produtos, vem sendo repensada através de discursos baseados na inclusão socioeconômica.

Portanto criar linhas de microcrédito para incentivar negócios sociais é uma garantia de liberdade e inclusão social que preservam a dignidade humana e protegem principalmente os direitos fundamentais da segunda geração.

Em termos de microfinanças, o Brasil além de ser um destino bastante atrativo para receber investimentos voltados a esse tipo de empreendimento financeiro, é fundamental observar que os recursos destinados devem cumprir um papel social, destacando a importância do crédito produtivo relacionado a boa educação financeira.

Observa-se que o silêncio da Constituição, sobretudo no âmbito da ordem econômica, é um silencio eloquente; por outras palavras; é o estilo da tradição laissez da legalidade civil própria de uma sociedade econômica pontualmente assegurada por garantias de direitos fundamentais (liberdade de propriedade; liberdade de reunião etc...), mas não positivamente definida em termos materiais. Isso não quer dizer que não 
Artigo original

Hegemonia - Revista Eletrônica de Relações Internacionais do Centro Universitário Unieuro

ISSN: $1809-1261$

UNIEURO, Brasília, número 15, 2015, pp. 151-183.

se pode dar o primeiro passo indicado histórico-constitucionalmente, no sentido de se passar uma Constituição Liberal para uma Constituição do Estado Social.

2. Bancarização pública brasileira e ações de inclusão social

A bancarização do setor público brasileiro, além da disputa comercial no setor, deve promover inclusão social e educação financeira simultaneamente, uma vez que a reinserção no mercado de trabalho através de políticas públicas, pode gerar o aumento da mão de obra qualificada e proporcionar uma movimentação financeira, a qual deve ser administrada de forma a aumentar a circulação da moeda, fortalecendo a economia do país e a influência do banco no cenário mundial.

A inclusão financeira das pessoas menos favorecidas oferece um grande potencial para impulsionar a economia das regiões nas quais esse segmento se concentra, trazendo esse público à economia formal, possibilitando ao Estado intervir fortemente nas funções basilares de bem estar social.

Como exemplo, Yunus durante sua estada em São Paulo, citou a produção de iogurte fortificado em Bangladesh, afirmando que foi um sucesso. "A empresa recebe pelo investimento, cobre os custos e garante que crianças tenham alimento de maior valor".

Os microcréditos impulsionam os negócios sociais que buscam impacto socioambiental positivo gerado por meio do próprio core business do empreendimento, ou seja, a atividade principal deve beneficiar diretamente pessoas com faixa de renda mais baixas, as chamadas classes C, D e E.(SEBRAE 2013) 
Artigo original

Hegemonia - Revista Eletrônica de Relações Internacionais do Centro Universitário Unieuro

ISSN: $1809-1261$

UNIEURO, Brasília, número 15, 2015, pp. 151-183.

Para exemplificar, A Social Traders da Austrália é uma organização sem fins lucrativos, fundada em 2008, com a missão de apoiar e incentivar a criação de negócios sociais comercialmente viáveis em toda a Austrália. Por meio de trabalhos com o governo, comunidades, empresas e parceiros de pesquisa, a organização pretende: aumentar a conscientização sobre os negócios sociais e demonstrar seus benefícios; abrir mercados para produtos e serviços de negócios sociais; aumentar o financiamento disponível para iniciar e desenvolver negócios sociais; desenvolver a capacidade dos empreendimentos para negociar com sucesso; e apoiar a coordenação do desenvolvimento de negócios sociais na Austrália.(SEBRAE2013)

Além de contribuir com o próprio empreendedor, o microcrédito produtivo orientado cria um ciclo virtuoso que leva benefícios a todo o entorno do negócio: cerca de $70 \%$ da renda gerada nesses empreendimentos circula dentro da comunidade. $O$ faturamento de uma pequena mercearia, por exemplo, se transforma na renda pessoal do empreendedor, que por sua vez concentra a maior parte do seu consumo em estabelecimentos de comércio e serviços oferecidos por outros moradores na vizinhança e gera um ciclo de desenvolvimento local, senão vejamos:

Ainda quando criança, um menino aprendeu o ofício de consertar bicicletas e motocicletas na oficina do irmão, em Araçagi, na Paraíba. Mais tarde, mudou-se para João Pessoa, com a irmã, e começou uma pequena oficina de reparo de bicicletas na casa da irmã. Com o sucesso do empreendimento, alugou uma garagem e mudou seu negócio para ali. Buscou depois um ponto comercial que, devido às dificuldades financeiras, tornou-se também sua moradia. Em 2006, o senhor contratou $R \$$ $1.000,00$ de empréstimo com um banco para capital de giro e compra de 
Artigo original

Hegemonia - Revista Eletrônica de Relações Internacionais do Centro Universitário Unieuro

ISSN: $1809-1261$

UNIEURO, Brasília, número 15, 2015, pp. 151-183.

material para a oficina, abrindo finalmente seu próprio ponto comercial. Até 2011, já possuía casa própria, outros empreendimentos e dois funcionários registrados em sua oficina.(CEBDS 2013)

Desta forma, os incentivos a microcréditos relacionados a negócios sociais relacionados a bancarização do setor público, podem agregar rentabilidade às instituições financeiras, aumentando sua influência no sistema econômico mundial, o que antes não acontecia, devido à inviabilidade econômica e os grandes investimentos em políticas públicas protecionistas, desviando o foco de suas principais funções do governo.

Desde modo, a necessidade do Estado de intervir em outras áreas seculares e vultosos investimentos em políticas assistencialistas, fez com que a população ficasse à mercê de "ações emergenciais" para garantir o mínimo de dignidade. O desvio das funções pode gerar o que Chomsky denomina de Estados fracassados, onde a população sofre com problemas sociais de vilolência e os governantes agem ilegalmente para suprir as questões negligenciadas.

Para Noam Chomsky (2009):

Os Estados fracassados não têm capacidade de dar segurança aos seus cidadãos e se posicionam fora do alcance das leis.

Neste sentido, fornecer possibilidades para que o indivíduo tenha capacidade de desenvolver sua liberdade e tornar-se produtivo, é uma ação de proteção à dignidade humana, tendo em vista a obrigação de proteção do Estado ao cidadão. Saúde, educação e segurança são deveres do Estado e sua principal função é proporcionar ferramentas para que seu povo possa desenvolver habilidades que irão proporcionar a liberdade de usufruir igualmente das benfeitorias sociais e coletivas. 
Artigo original

Hegemonia - Revista Eletrônica de Relações Internacionais do Centro Universitário Unieuro

ISSN: $1809-1261$

UNIEURO, Brasília, número 15, 2015, pp. 151-183.

Em 1976, o Projeto Banco Grameen, idealizado pelo seu fundador Muhammad Yunus, criou possibilidades de auto emprego a uma multidão de desempregados rurais em Bangladesh com facilidades creditícias para homens e mulheres pobres. Esta ação gerou uma motivação e uma movimentação na economia do setor ora estagnada.

Nesta linha de raciocínio, os bancos públicos brasileiros devem gerar ações de cooperativismo de crédito para que as pessoas de baixa renda possam ser beneficiadas pelos microcréditos e saiam da situação de extrema pobreza, viabilizando a expansão da oferta de capital, com possibilidade de liberdade contratual, comercial e pessoal.

Yunus ficou convencido que os pobres são merecedores de confiança, pois pagam seus pequenos empréstimos a atividades produtivas.

Sendo assim, na medida em que um sistema social está baseado em desigualdade ou a permanência desigual, formas de expressão da desigualdade influem genericamente na realização do direito, por causa da possibilidade de normatização jurídica de conteúdos políticos oriundos de lutas populares e representativas da sociedade complexa hodierna.

Desta forma, como o setor bancário brasileiro é o maior e mais desenvolvido da América Latina, a forte atuação do banco público brasileiro nas questões sociais e na promoção de políticas públicas, gera uma força coletiva de maior impacto no setor financeiro e conseqüentemente na economia, oferecendo maior estabilidade ao cidadão, maior segurança da coletividade e possibilidade de direcionar novos investimentos nas funções primárias governamentais.

Ressalta-se que no Brasil o mercado de crédito tradicional continua menos desenvolvido, o que prejudica a eficácia das políticas de inclusão social na bancarização, uma vez que o indivíduo necessita de impulso para iniciar 
Artigo original

Hegemonia - Revista Eletrônica de Relações Internacionais do Centro Universitário Unieuro

ISSN: $1809-1261$

UNIEURO, Brasília, número 15, 2015, pp. 151-183.

suas atividades laborais ou empreendedoras e manter-se ativo no sistema financeiro.

Para Monzoni Neto (2006), os microcréditos devem ser vistos como uma oportunidade e os gestores públicos devem refletir positivamente sobre a possibilidade de utilização do microcrédito como política de geração de renda, em escala, dentre as alternativas de política social no Brasil. E para que $\mathrm{o}$ setor financeiro compreenda que o micro crédito produtivo orientado pode resultar na incorporação de novos clientes com bom histórico de crédito ao sistema bancário.

O Estado deve motivar a criação de uma perfeita relação da capacidade humana de criar riqueza, gerar lucros e laborar em prol de mais conforto para a existência humana de forma constante, duradoura e não apenas uma falsa ideia de liberdade momentânea de ações protecionistas.

As ações de educação financeira no contexto da bancarização pública brasileira, além de promover o aumento da força competitiva do banco, é uma forma de proporcionar a permanência nos indivíduos no sistema.

Neste sentido, a implantação e execução das políticas públicas de inclusão social, o até então desprovido de recursos e potencialidades, passa a desenvolver qualidades laborais como garantia de liberdade no contexto econômico atual.

Para Amartya Sen (2000):

Há muitos males sociais que privam as pessoas de viverem minimamente bem: a pobreza extrema, a fome coletiva, a subnutrição, a destituição e marginalização sociais, a privação de direitos básicos, a carência de oportunidades, a opressão e a insegurança econômica, política e social.

A reinserção no mercado de trabalho e permanência no sistema financeiro da nova classe de "clientes" muda o cenário como forma de exercício da 
Artigo original

Hegemonia - Revista Eletrônica de Relações Internacionais do Centro Universitário Unieuro

ISSN: $1809-1261$

UNIEURO, Brasília, número 15, 2015, pp. 151-183.

justiça social, uma vez que a geração de empregos e renda, devido o acesso ao microcrédito e microfinanças ameniza os malefícios causados ao cidadão de baixa renda do atual sistema capitalista.

Para Prahalad (2009):

se pararmos de pensar nos pobres como vítimas ou como um fardo e começar a reconhecê-los como empreendedores incansáveis e criativos e consumidores conscientes de valor, um mundo totalmente novo de oportunidades se abrirá.

As políticas públicas são remédios para os malefícios do desenvolvimento, do progresso e da mundialização do capitalismo, uma vez que os bolsões são cada vez mais massificados pela brutal disputa macroeconômica e a concentração de riquezas é um principal fato gerador de desigualdades sociais.

A possibilidade de gerar maior distribuição de renda diminui os problemas gerados pela concentração de riquezas. As políticas públicas devem ser motivadas por necessidades de inclusão e não por dependência de ações assistencialistas ou protecionistas que não impulsionam a economia, nem possibilitam o exercício da cidadania.

Para Vicente Faleiros (2009):

políticas públicas como o conjunto de diretrizes governamentais voltadas, legalmente, ao propósito de se criar condições de desenvolvimento sócioeconômico em favor de uma dada população

de um determinado país. Obviamente esse conceito diz respeito à interferência estatal na vida social para a perseguição de objetivos pautados sob a égide do bem comum. As definições de políticas públicas sempre dizem respeito à alocação de recursos financeiros, 
Artigo original

Hegemonia - Revista Eletrônica de Relações Internacionais do Centro Universitário Unieuro

ISSN: $1809-1261$

UNIEURO, Brasília, número 15, 2015, pp. 151-183.

resultado de múltiplos interesses aos quais o Estado deve atender racionalmente e, em consonância com a vontade da sociedade, executar programas que levem em consideração oportunidades e necessidades coletivas. As políticas públicas, como ações estatais, assumem múltiplos aspectos. Do ponto de vista econômico, estão relacionadas à dimensão da racionalidade quanto à escolha de prioridades, visto que os recursos.

Os direitos sociais das pessoas que formam os bolsões foram prejudicados concomitantemente ao desenvolvimento tecnológico e industrial.

Para Vera Telles (1999):

(...)os efeitos devastadores das mudanças em curso no mundo contemporâneo, demolindo direitos que mal ou bem garantem prerrogativas que compensam a assimetria de posições nas relações de trabalho e poder, e fornecem proteções contra as incertezas da economia e os azares da vida.

A injustiça social se tornou presente nos diversos momentos históricos do capitalismo. A exploração da mão de obra contradiz o preceito de liberdade e a exclusão social contradiz a teoria do Estado de Bem Estar Social.

O presidente da Fundação Grameen Foundation USA, Alex Counts, afirma que o "Estado do Mundo", retratado por meio de indicadores sociais e ambientais, revela uma fotografia de degradação completa e futuro sombrio.

Nesse cenário, políticas públicas de redução de pobreza, em escala, passam a ser demandadas com urgência, trazendo luz aos programas de microfinanças, de uma maneira geral, e de microcrédito, de maneira particular. 
Artigo original

Hegemonia - Revista Eletrônica de Relações Internacionais do Centro Universitário Unieuro

ISSN: $1809-1261$

UNIEURO, Brasília, número 15, 2015, pp. 151-183.

Desta maneira, é dever do Estado brasileiro impor ações que garantam a condição de cidadão em todas as suas esferas, uma vez que os direitos individuais e coletivos da massa foram lesados em prol da ganância e disputa de poder.

A bancarização do setor público brasileiro é uma forma do Estado de garantir condições de sobrevivência aos indivíduos que sofreram com a pressão externa do sistema difuso do capitalismo mundializado, bem como promover a cidadania e impulsionar a economia do país.

Futuramente as experiências de microfinanças vão relatar com evidências comprobatórias as melhorias de geração de renda, redução de pobreza e melhoria nos indicadores econômicos regionais e nacionais.

3 Considerações finais

A inovação tecnológica, a expansão comercial, a soberania, o Estado de Bem Estar, o Estado de Liberdade, o conceito de justiça social, a necessidade de adquirir conhecimentos e as alianças políticas são virtudes do Estado Moderno. Os ideais revolucionários de liberdade, igualdade e fraternidade são influentes até a idade contemporânea.

O grande defeito do Estado Moderno é a exclusão da grande parte da população das virtudes e ideais da classe dominante, bem como a incapacitação ao mercado de trabalho que se torna cada vez mais exigente e competitivo com a globalização e a disputa comercial.

A injustiça social, as formas indignas de sobrevivência, a exploração de trabalhadores, a dificuldade de acesso a educação, a impossibilidade de acumular riquezas e competir isonomicamente no mercado em expansão, a submissão as regras impostas e a privação de liberdades individuais 
Artigo original

Hegemonia - Revista Eletrônica de Relações Internacionais do Centro Universitário Unieuro

ISSN: $1809-1261$

UNIEURO, Brasília, número 15, 2015, pp. 151-183.

assolam o povo que lutou por liberdade, buscou proteção e conquistou o direito de propriedade. Este povo se tornou refém da minoria que detém o poder de manipular o Estado e impor suas regras.

Neste contexto de extrema competição e exclusão social, a bancarização do setor público é uma importante ferramenta de apoio ao Estado na implementação de políticas públicas que auxiliam os indivíduos na busca de reinserção social.

Impulsionar a economia com a entrada da nova classe de "clientes" ao mercado de trabalho é promover a cidadania e proporcionar aos bancos públicos possibilidade de aumentar de forma permanente sua clientela e poderio no contexto econômico mundial.

Buscar a liberdade do povo pelo desenvolvimento de uma condição crítica do bem estar social, por uma capacidade de expressar e reivindicar os direitos minados historicamente, como forma de resolver o âmago da indignidade gerada pela submissão imposta, é proporcionar possibilidades de qualificação pessoal em prol de uma política protecionista que priva o indivíduo de expandir seus limites no sistema capitalista globalizado.

As ações protecionistas que causam a comodidade dos beneficiários devido uma sensação de exclusão e incapacidade não solucionada devem ser substituídas por políticas de incentivos laborais.

Nesta linha de raciocínio os negócios sociais e a concessão de microcréditos devem ser vistos como uma oportunidade de crescimento da economia. Orientar os gestores públicos para que estes possam refletir na condução dos novos clientes a uma alteração do "status quo" de estagnação, para uma liberdade pautada na produtividade além da inclusão social, fortalece a economia, bem como a força coorporativa no banco, gerando um bom histórico bancário. 
Artigo original

Hegemonia - Revista Eletrônica de Relações Internacionais do Centro Universitário Unieuro

ISSN: $1809-1261$

UNIEURO, Brasília, número 15, 2015, pp. 151-183.

A necessidade de gerar uma visão e missão política de maior intervenção do Estado nas questões ligadas a saúde, educação e segurança, é uma forma de minimizar o desrespeito aos direitos fundamentais. As Instituições Públicas devem zelar pelos princípios constitucionais, bem como, proporcionar melhor qualidade de vida ao cidadão, obtida com o desenvolvimento de habilidades individuais e força laboral, para atingir a liberdade social.

Metódico-juridicamente, contudo, há de ser levada em conta a previsão pessimista, alimentada pela suposta ingovernabilidade dos Estados Constitucionais, como variante ao menos possível, tendo por conseqüência a redução dos elementos democráticos e o incremento dos elementos autoritários do sistema político, inclusive da família constitucional ocidental.

É marcante enquanto razões do afastamento do "estado fático" em face do "estado de dever-ser" próprio do Estado de Direito, que é a carência de realização fática do direito vigente ou é um interesse de não colocar em evidência as verdadeiras razões que tornam as decisões hodiernas transparentes ou não.

Para Hanna Arent (2009):

O fim da vida é a morte, mas o homem não vive por causa da morte. Ele vive porque é uma essência vital; e ele não pensa por causa de um resultado qualquer, mas porque é uma essência 'pensante, isto é, meditativa. 
Artigo original

Hegemonia - Revista Eletrônica de Relações Internacionais do Centro Universitário Unieuro

ISSN: $1809-1261$

UNIEURO, Brasília, número 15, 2015, pp. 151-183.

REFERÊNCIAS BIBLIOGRÁFICAS

ARENDT, Hannah. A condição humana. 10a ed. - Rio de Janeiro: Forense Universitária,2003.

BANCO CENTRAL DO BRASIL. Relatório de inclusão financeira, n. 2, 2011. BONAVIDES, Paulo. Curso de Direito Constitucional. São Paulo: Malheiros, 2003.

CARVALHO, José Murilo. Cidadania no Brasil - o longo caminho. Rio de Janeiro: Civilização Brasileira, 2006.

CEBDS - Micrifinanças: Microcrédito e microsseguros no Brasil, 2013.

CHESNAIS, F. A mundialização doCapital. São Paulo: Xamã, 1996.

CHOMSKY, Noam. Estados Fracassados. Rio de Janeiro: Bertrand Brasil, 2009

DALLARI, Dalmo. Elementos de Teoria Geral do Estado. 32 edição - 2013 FRITSCH, Winston. Apresentação. In: SMITH, Adam. Investigação sobre a natureza e causas da riqueza das nações. Tradução de João Baraúna. São Paulo: Abril Cultural. V.1,1983

HAYEK, Friedrich A. O Caminho da Servidão. Trad. De Leonel Vallandro. 2a ed. São Paulo: Globo, 1977.

HOFLING, Heloisa. Estado e Políticas (públicas) sociais. Cadernos CEDES, Campinas no 55, p. 30-4, novembro de 2001

LENZA, Pedro. Direito Constitucional Esquematizado. São Paulo: Malheiros 2006, pp. 517.

MONZONI NETO, M. P. Impacto em renda do microcrédito: uma investigação empírica sobre geração de renda do crédito popular solidário (São Paulo confia), no município de São Paulo. 2006. 195P. Tese (Doutorado em Administração Pública e Governo) - Escola de 


\section{Artigo original}

Hegemonia - Revista Eletrônica de Relações Internacionais do Centro Universitário Unieuro

ISSN: $1809-1261$

UNIEURO, Brasília, número 15, 2015, pp. 151-183.

Administração de Empresas de São Paulo da Fundação Getulio Vargas, São Paulo, 2006.

MULLER, Friedrich. Metódica Jurídica e Sistema Político. Joinvile, 2014.

SALVADOR, Evilasio. Fundo público e seguridade social no Brasil. São Paulo: Cortez, 2010.

SEBRAE. Diretrizes Estratégicas para Atuação do sistema SEBRAE no mercado de negócios sociais, 2013.

SEN, A. K. Desenvolvimento como liberdade. São Paulo: Companhia das Letras, 2000

TELLES, Vera. Direitos Sociais. Afinal do que se Trata? Belo Horizonte, Ed. UFMG, 1999 